\title{
AS RESPOSTAS DA INTELLIGENTSIA LUSITANA AO PORTUGAL DE FINS DE OITOCENTOS: O NACIONALISMO E O MESSIANISMO LITERÁRIOS
}

\author{
Annie Gisele Fernandes \\ Universidade de São Paulo
}

Com D. Sebastião morreu a grandeza da Pátria. Se a Pátria tornar a ser grande, voltará, ipso facto, D. Sebastião, não só simbolicamente falando, mas realmente.

Fernando Pessoa

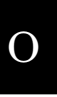

sentimento generalizado de frustração e decadência que caracterizou o Portugal do século XIX, patente na postura implacável da intelligentsia portuguesa naquela centúria, fundamentou-se na constatação de que no Portugal coevo era impossível reconhecer aquele país que havia conquistado mares e continentes, que havia sido grande potência na época dos descobrimentos e expansão marítima. O Portugal oitocentista, ao contrário, era um país extremamente frágil e inferiorizado com relação à Europa desenvolvida; era um país submisso e subalterno a Inglaterra e que não conseguia reverter o quadro de atraso e decadência em que se encontrava desde o início do século; era um país que as várias gerações de intelectuais e políticos que se sucederam ao longo do referido período não conseguiram "regenerar”, apesar das várias tentativas de reerguê-lo. A esse sentimento de decadência veio somar-se o choque que o Ultimatum (1890) causou, pondo fim ao sonho de restabelecer Portugal através da criação de um novo império colonial na África, com a união de Angola e Moçambique através da conquista das terras que as separavam.

Se, por um lado, o pessimismo e a idéia de decadência perpassaram também a Europa ultracivilizada e se o Simbolismo, em gestação no cenário cultural da Europa desde 1880, está inserido num contexto europeu de crise quanto ao paradigma cultural dominante - o positivismo, o naturalismo, o 
racionalismo - e de pessimismo, que abrange desde o sentimento de decadência dos franceses subseqüente a sua derrota na Comuna de Paris (1870) ao dos portugueses depois do Ultimatum (1890), por outro, o que diferenciava o pessimismo e idéia de decadência na conjuntura européia dos que assolaram Portugal era o fato de que, neste país, os problemas e as dúvidas decorrentes do domínio da razão e da técnica foram acrescidos da constante situação de crise por que passava, o que possibilitou a exploração de novas vias de desenvolvimento temático dentro daquela corrente literária que se consolidava. ${ }^{1}$ Em Portugal, as condições culturais e as condições sócio-político-econômicas finisseculares, bem como o fomento da política de colonização das terras portuguesas no continente africano depois do Ultimatum, acentuaram o ardor passadista e africanista (res)surgido na década de 1880 com as comemorações dos centenários de Camões e de Pombal, com a polêmica do Tratado de Lourenço Marques, e foram favoráveis, no contexto do Simbolismo-Decadentismo, à emersão do nacionalismo literário, muitas vezes chamado Neo-Romantismo lusitanista. ${ }^{2}$

O nacionalismo literário, lusitanista, tradicionalista, da década de 1890 - com inclinações passadista, folclorista, ruralista, neogarrettista naquela época; saudosista e integralista nos primeiros anos da segunda década de Novecentos - caracteriza-se pelo voltar-se às paisagens, gentes, crenças e costumes tipicamente nacionais, pelo regresso, sobretudo como evasão do

Ao tratar do pessimismo no Portugal do fim do século XIX e da literatura que então se produziu, Bernard Martocq destacou que: Le pessimisme raisonné et systématique est ainsi dépassé par une autre forme sentimentale et viscérale de pessimisme, celle-là même qu'Antero reconnaissait en 1890 lorsqu'il écrivait à la suit d'Horace Walpole: 'A vida é uma tragédia para os que sentem e uma comédia para os que pensam'. Et, ajoutait-il, c'est à la première catègorie que nous appartenons. C'est cette maladie qui va se répandre à partir de 90 et ravager les esprits avec plus ou moins de virulence selon le terrain qu'elle rencontrera. Dans le cas les plus sérieux, elle prendra la forme d'une névrose [...]. Dans le cas les plus bénins, il ne s'agira que d'une maladie infantile ou d'une tribut payé à une mode [...] ("Le pessimisme au Portugal”. In: Arquivos do Centro Cultural Português, v. V, Paris, Fundação Calouste Gulbenkian, 1992, p. 422-423).

2 Segundo José Carlos Seabra Pereira, "En ce qui concerne le Néo-Romantisme lusitaniste il faut nuancer le problème de la composante historiciste. Son apparition date de 1885 environ et son épanouissement va de pair avec la montée des campagnes militaires en Afrique, quoiqu'il puisse profiter aussi, en tant que compensateur, de la vexation de l'Ultimatum. [...]" (Cf. Idem, p. 10). 
presente deceptivo, aos elementos populares, à natureza, à simplicidade pacificantes, à longínqua época gloriosa e imperial. E, não apenas como evasão, como tendência alienante perante a consciência da ruína portuguesa, da distância que o separava da civilização, o regresso ao Romantismo de cunho nacionalista e tradicionalista, postulado por Almeida Garrett, parecia conter uma resposta para a questão da busca da identidade, também principiada com aquele autor, visto que tinha como temas os símbolos do Portugal passado que o diferenciavam da Europa civilizada e que, de certo modo, remetiam ao passado glorioso.

Uma das manifestações poéticas do desencanto e pessimismo para com a Pátria foi a teorização neogarrettista postulada por Alberto de Oliveira nas Palavras Loucas (1894) ${ }^{3}$ - teorização de que o autor fez bandeira o Só (1892), de António Nobre, por considerar que as pessoas do povo que esse poeta evoca em muitos de seus poemas, as suas tradições e superstições, a sua linguagem, as suas canções e estórias, o pitoresco das aldeias portuguesas são, numa perspectiva muito aquém da estético-poética levada à cabo por Nobre, os elementos que conduziriam a "uma Litteratura portugueza nova, pujante, toda de regresso às tradições” (OLIVEIRA, 1894, p. 36), definida como neogarrettista. Teorizado como posição anti-racionalista e anti-naturalista, como desejo de desintelectualizar-se, o neogarrettismo foi refutado por Eça de Queiroz que, tendo recebido as Palavras Loucas de seu próprio autor, lhe escreveu ressaltando que "o tradicionalismo em Literatura já foi largamente experimentado, durante trinta largos anos, de 1830 a 1860 - e certamente não resultou dele aquela renovação moral de que Portugal necessita e que o meu amigo [A. de Oliveira] dele espera". Sobretudo porque "o dever dos homens de inteligência, num país abatido, tem de ser mais largo do que reconstruir em papel o castelo de Lanhoso ou chamar as almas a que venham escutar os rouxinóis do Choupal de Coimbra" (QUEIROZ, 1983, p. 327).

3 Em trabalhos anteriores discuti a leitura neogarrettista da obra de António Nobre e os principais autores e respectivos textos em que tratam desse tema. Consultar, a esse respeito, Annie Gisele Fernandes, A Estrutura Dialógica em Poemas do Só de António Nobre (Dissertação de Mestrado, Campinas / Unicamp, Instituto de Estudos da Linguagem, 1996, especialmente páginas 42 a 45) e Neogarrettismo e messianismo no século XIX: o Lugar de António Nobre (Tese de Doutorado, São Paulo / Universidade de São Paulo, Faculdade de Filosofia, Letras e Ciências Humanas, 2001). 
Essa oposição de Eça de Queiroz ao nacionalismo limitado ao campo literário, a sua defesa à necessidade de ação, bem como o seu estímulo a ela, estão patentes em $A$ ilustre casa de Ramires (1897) ${ }^{4}$ através do exemplo de Gonçalo Ramires, o último descendente daquela família. Se, nessa obra, Eça pôs em destaque, por um lado, os costumes, as tradições, as fórmulas mentais, as características tradicionais de Portugal - do mesmo modo que fez em As cidades e as serras -, aproximando-se, dessa forma, da geração nacionalista de 1890, como pensa António José Saraiva (1995, p. 192), por outro, o romancista nos mostrou Gonçalo Ramires rejeitando essas opções tradicionalistas que não poderiam conduzir Portugal à "renovação moral" e voltando-se para a ação colonizadora na África, que possibilitaria a recuperação econômica daquele País. No primeiro capítulo de $A$ ilustre casa de Ramires, Gonçalo, o representante de uma raça que, como Portugal, degenerou, é estimulado pelo patriota José Lúcio Castanheiro a escrever uma novela histórica que revele Portugal, que ressuscite tradições e antigos varões, uma vez que "a pena agora, como a espada outrora, edifica reinos..." (QUEIROZ, 1997, p.19). Além disso, aquela personagem também chamada de "Castanheiro Patriotinheiro" e fundadora do semanário A Pátria, aparece como uma alegoria dos neogarrettistas, pois deseja, através da literatura que "leva a tudo em Portugal” (p. 19), “despertar não só na mocidade Acadêmica, mas em todo o país, [...] o amor tão arrefecido das belezas, das grandezas e das glórias de Portugal!”, “reatar a tradição” (p. 14), “ressuscitar [...] varões, e mostrar neles a alma façanhuda, o querer sublime que nada verga, [uma vez que isso] é uma soberba lição aos novos... Tonifica” (p. 19). As obras que seguissem essa "profissão de fé” operavam, aos olhos de Castanheiro, "um salutar retrocesso ao sentimento nacional” (p. 15). Entrementes, no final do livro, Gonçalo, transformado pela intervenção dos seus ancestrais, decide-se pela ação e parte para África. A partida de Gonçalo para o continente africano no paquete Portugal com o intuito de explorar uma concessão agrícola e o seu regresso vitorioso à nação portuguesa apresentam-se como símbolos da pátria, remetem-nos ao destino colonizador de

4 Nesse ano, a obra em estudo foi publicada na Revista Moderna. Revista pelo autor, ela será publicada em volume postumamente, em 1900. 
Portugal e, desse modo, efetivam o intuito de "reatar ativamente a tradição", como nos mostra o seguinte trecho:

Aquele todo de Gonçalo, [...]. A desconfiança terrível de si mesmo, que o acobarda, o encolhe, até que um dia se decide, e aparece um herói, que tudo arrasa... Até aquela antiguidade de raça, aqui pegada à sua velha Torre, há mil anos... Até agora aquele arranque para a África... Assim todo completo, com o bem, com o mal, sabem vocês que ele me lembra? Quem? - Portugal (QUEIROZ, 1997, p. 263).

Não obstante, nessa obra a rememoração da história pátria, dos acontecimentos históricos em que os antepassados ilustres de Gonçalo Ramires participaram não remete apenas ao nacionalismo literário; ela permite entrever outra maneira de resposta da intelligentsia lusitana em fins de Oitocentos: o messianismo literário - messianismo lançado em bases modernas por Oliveira Martins na sua História de Portugal -, uma vez que através dela Eça de Queiroz nos apresenta a aventura sebastianista em Alcácer-Quibir, onde dois antepassados de Gonçalo "encontra[ra]m morte soberba" (QUEIROZ, 1997, p. 13) e um outro, chamado Paulo Ramires, morreu voluntariamente depois da morte do rei. E é justamente esse ascendente da familia Ramires o último a aparecer no desfile dos fantasmas dos Ramires que viveram entre a Revolução de 1383 e a aventura desastrosa em África em 1580 e que fazem a entrega das armas a Gonçalo.

O episódio da entrega das armas, feita pelos Ramires ilustres que, de acordo com o que Eça nos sugere, correspondem aos varões da dinastia de Avis, nos remete ao misticismo de Nuno Álvares e sua espada, nos remete a uma investidura messiânica, à investidura de uma heróica ancestralidade mítica simbolizada pela entrega das armas, como podemos ver numa passagem como a que segue: "Era, em torno do leito, um heróico reluzir e retinir de ferros. E todos soberbamente gritavam: 'Ó neto, toma as nossas armas e vence a sorte inimiga!...” (QUEIROZ, 1997, p. 205).

O desfecho do diálogo entre Gonçalo e esses seus antepassados que lhe aparecem e lhe entregam as armas - "Mas Gonçalo, espalhando os olhos tristes pelas sombras ondeantes, volveu: - 'Ó avós, de que me servem as vossas armas - se me falta a vossa alma?...” (p. 205) - explicita uma outra questão sempre 
presente na interpelação de Portugal feita por Antero de Quental, Oliveira Martins, Guerra Junqueiro. Trata-se da falta da "alma" que faria com que Gonçalo, alegoria de Portugal, saísse do estado de apatia, submissão e opressão e "vale[sse] pela vontade - [pois] só no exercício da vontade reside o gozo da vida" (QUEIROZ, 1997, p. 203); trata-se da "alma" que faria com que Portugal retomasse seu lugar de grande potência. Entretanto, é a partir desse episódio que se opera, como vimos, a transformação de Gonçalo, que se sente amado e incorporado pelos seus antepassados e recupera a alma, a alma portuguesa.

Está evidente, portanto, que n'A ilustre casa de Ramires desenvolvem-se duas histórias: uma, a de Gonçalo Ramires, ambientada no tempo presente; outra, a dos seus antepassados ilustres, referente ao passado histórico de Portugal. Está claro também que essas duas histórias estabelecem o confronto entre o Gonçalo-Portugal contemporâneo, representante decadente de uma raça heróica, e o Gonçalo-Portugal ancestral, dos heróis medievais, que leva à transformação daquela personagem. É, novamente, a dicotomia passado-presente. E se Eça, como Almeida Garrett havia feito no Frei Luís de Souza, propôs a saída para a situação de decadência do seu Portugal coetâneo através da ação no presente, essa ação só foi possível depois de Gonçalo ter recuperado a alma portuguesa, heróica, dos seus antepassados da época anterior à de decadência.

Com relação a $A$ cidade e as serras (1901), é interessante notar, além do regresso de Jacinto à paz virgiliana de uma quinta no Douro, do antigo palácio de seus avós, algumas passagens em que Eça considerou o messianismo. Uma é a que relata a atitude do avô de Jacinto, que no dia da chegada de D. Miguel a Portugal, ergueu um monumento em que o rei-Salvador, "tornado S. Miguel, branco, d'aureola e azas de Archanjo", acabava com o perigo revolucionário, o "Dragão do Liberalismo, que se estorcia vomitando a Carta" (QUEIROZ, 1933, p. 7). Em outro momento, o autor faz referência ao paralelo entre D. Sebastião e D. Miguel ao nos mostrar que Jacinto, pelo seu interesse pelos inferiorizados, era tido, por uns, como D. Sebastião, por outros, como agente de D. Miguel. Eça de Queiroz aponta também o messianismo inato do povo português no episódio em que, devido ao questionamento e espanto de Jacinto sobre a existência em Portugal de sebastianistas ainda naquela altura, Zé Fernandes lhe diz: “Todos o somos ainda em Portugal, Jacintho!", e, explicando a seu amigo o fenômeno, completa: "Na serra ou na cidade cada um espera o seu D. Sebasti- 
ão. Até a loteria da Misericordia é uma fórma de Sebastianismo" (QUEIROZ, 1933, p. 335). Parece possível entrever aqui um indício da crítica que a Geração de 70 explicitamente fez ao Portugal que se apoiava em elementos "mortos", como afirmou Oliveira Martins; um prenúncio da bela e inexorável "Psicanálise mítica do destino português", segundo a qual aquele País espera "do milagre, no sentido mais realista da palavra, aquilo que, razoavelmente, não podia ser obtido por força humana", ao Portugal apegado ao "sebastianismo [que] representa a consciência delirada de uma fraqueza nacional, de uma carência, e essa carência é real" (LOURENÇO, 1992, p.22).

Reportando-nos ainda à conjuntura funesta do Ultimatum, em que se desenvolveram o tradicionalismo e o messianismo literários, em que o antibritanismo e os questionamentos acerca da identidade e do destino portugueses foram freqüentes, em que a sensação de morte da pátria avultouse, vemos aparecer uma das respostas mais violentas da intelligentsia portuguesa à afronta britânica: Finis Patriae, de Guerra Junqueiro.

Nessa obra escrita ao longo de 1890, Guerra Junqueiro retrata a decadência da Pátria, que "é morta", numa seqüência de imagens e descrições em que estão patentes, por exemplo, a morbidez, a degradação da raça e da sociedade, a obscuridade ("Noite negra sem astros, sem faróis", "Qual se fora de noite e em matagal bem denso" (JUNQUEIRO, 1967, p.42 e 48) e as imagens crepusculares (no capítulo intitulado "A Inglaterra") - características do Decadentismo, que desde 1885 vinha se fortalecendo em Portugal. Em Finis Patriae, entretanto, mais do que a filiação decadentista, sobressai o tom panfletário e combativo com que o poeta evidencia a sua revolta contra a Inglaterra - referida como o "cão", a "pantera", "bêbeda impudente", "meretriz nefanda" - e contra a dinastia brigantina (os "porcos da vara de Bragança”) e um pessimismo intenso diante da ruína de seu País, assolado moral e socialmente, e cujas "Grandeza e glória ... tudo a rastros, / Tudo aos bocados, tudo em pó!” (JUNQUEIRO, 1967, p. 24). Indignado diante da derrocada de Portugal e da atitude britânica, o poeta considera que a conjuntura coetânea arrasou e ultrajou também a memória dos heróis antepassados, como podemos ver pelos versos que seguem:

Eram de bronze eterno, eram d'aço impoluto

Almas d'heróis, línguas d'espadas! 
Ei-lo o inimigo fero e bruto:

Como é que escala o meu reduto?

Às gargalhadas (1967, p. 22).

No entanto, apesar da consciência, expressa já na abertura da obra, de que "É negra a terra, é negra a noite, é negro o luar", resta ao poeta alguma esperança de regeneração pátria entrevista na sua evocação à "Mocidade das Escolas” para que lute pelo Portugal que “Não Morrerá!”. Esse verso, repetido como refrão em todas as estrofes, com exceção da última, completa-se nessa com o confiante “Reviverá!”. Mas para a revivescência de Portugal era preciso pôr fim à dinastia dos Braganças. Daí a sugestão ao regicídio: “Tiros ao longe numa luta acesa! / Rola indomitante a multidão... / Tocam clarins de guerra a Marselhesa... / Desaba um trono em súbita explosóo!...” (JUNQUEIRO, 1967, p.43).

A indignação causada pelo Ultimatum e pelo Tratado de 20 de Agosto, que lhe sucedeu, e a idéia de que a redenção de Portugal se realizaria com fim da dinastia brigantina - a grande e verdadeira responsável pelo desfazer da grandeza de Portugal -, com a morte do rei, é retomada por Guerra Junqueiro na Pátria, que é seqüência de Finis Patriae e constitui-se a partir da visão histórica apresentada por Oliveira Martins na História de Portugal. Como Oliveira Martins, que considerava que o processo de decadência de Portugal remontava a três séculos e que a situação agônica de Portugal iniciada com a aventura catastrófica de Alcácer Quibir era expiação dos pecados cometidos no Oriente, Guerra Junqueiro reputava que "as pátrias, como os indivíduos, só se regeneram sofrendo" e que "a Redenção vem da Paixão” (JUNQUEIRO, s.d., p.195).

Paixão e redenção são efetivamente as idéias centrais da cena que encerra a Pátria. Do “Portugal, rei do Oriente!" (idem, p. 182), crucificado e expirante, com os crimes e iniqüidades cometidos expiados pela sua agonia, ressurgiria, através da intervenção messiânica de Nuno Álvares, um novo Portugal. A reconstrução de Portugal e a alma que lhe falta viriam, portanto, do aparecimento de um novo "Nunalvares", a criança que nos versos finais da Pátria surge "aninhada nos braços" de "um aldeão senil e vagabundo" (idem, p. 183) e que, vibrando avidamente "numa alegria doida" ao ver a espada, o “montante de Nunalvares” (idem, p. 184), é misticamente revestida de ação 
salvífica. Estabelece-se, assim, a relação passado-presente-futuro, pois, ao mesmo tempo em que a dicotomia entre o passado e o presente acentua a decadência e flagelação deste - evidente, por exemplo, em

Que é da grandeza heróica do passado,

Que é das tôrres d'outrora olhando o mar?!...

Blocos no chão, vestidos d'heras,

Ameias, gárgulas, esferas,

Poeiras de sonhos, de quimeras,

Luto, nudez, desolação,

Eis os restos de tantos extermýnios,

De tanta dôr e tanta maldição!... - (p. 172),

é daquele mesmo passado que vem o elemento regenerador do porvir: "Luz enigmática, vem de longe, do fundo do passado, morrendo ao longe, em sonho, nas obscuridades do porvir..." (idem, p. 183).

Portanto, a imagem do aldeão senil carregando a criança, futuro Nuno Álvares, é ricamente simbólica, no sentido em que mostra que o Portugal presente e a sua reconstituição no futuro estão assentadas no passado que é o do Portugal aldeão, rural, onde impera a pureza da vida simples. Na simplicidade e pureza representadas pelo aldeão e pela criança está a expectativa de um novo porvir, prenunciado pelas "cotovias [que] gorjeiam", "saüdando a luz” (idem, p. 184), para a nação portuguesa, que, como Junqueiro sugere, será caracterizada pela ruralidade.

A expectativa messiânica expressa nos versos finais de Pátria e também nas Anotações que lhe foram apensas pode ser vislumbrada já na cena VIII, nas palavras do "Astrolugus", que, ao fazer a retrospectiva da História Nacional, descreveu a aventura de D. Sebastião e afirmou que ele não morreu em Alcácer-Quibir e que regressou a Portugal depois de meio século em que esteve "preso e débil", como patenteiam os versos:

E a morte não o quis: exâmine e desfeito, De lançadas crivado o arnez, crivado o peito, Sob o corcel tombou, por milagre inda vivo! Levaram-no depois sem acôrdo e cativo. Meio século preso e débil ... De repente, 
Num assomo de fúria e de cólera ardente,

Partiu grilhões, abriu o ergástulo fatal

E voltou livre, livre! ao seu torrão natal!... (p. 62).

Entretanto, $O$ Desejado D. Sebastião não retornou à pátria e a substituí-lo temos Nuno Álvares que, ressurgindo misticamente, acordaria a população e poderia dar a Portugal a "Alma" que lhe faltava, poderia "Fazer de quatro milhões de espíritos um só espírito, juntar quatro milhões de vontades numa só vontade” (JUNQUEIRO, p. 205), porque:

[...] a abnegação e o sacrifício de todos, a comunhão unânime e grandiosa num ideal de Justiça, num ideal de Pátria, transfigurar-nos-ia por encanto, de povo de chatins em povo de heróis, de mortos com direito ao cemitério, em gente viva com direito ao pão, com direito à luz (idem, p. 205).

Da destruição e ressurreição do Portugal na última cena da obra em questão, percebemos já a mensagem de Guerra Junqueiro: eliminando o Portugal monárquico bem como a realeza, o Republicanismo surgia como "a fórmula extrema de salvação pública" (idem, p. 201). Republicano, Junqueiro defendia que a regeneração viria com a implantação daquele sistema. Desse modo, Finis Patriae e Pátria nos mostram que as promessas de redenção do messianismo literário à serviço do republicanismo foram, como não poderiam deixar de ser, coincidentes com as promessas de redenção da propaganda republicana. Com essas obras, Junqueiro realizava o projeto republicano de

associar, crescentemente, a denúncia da monarquia e da tutela inglesa com as promessas de redenção do império e da grandeza nacional perdida, apresentando-se, assim, como a única alternativa que, encarnando a 'alma nacional', poderia salvar o País” (CATROGA, 1996, p. 567).

Era, cada vez mais, a República sendo identificada com o nacionalismo "republicano e patriota tornaram-se sinônimos" (s.d., p. 201), enfatizava Guerra Junqueiro. Era, uma vez mais - e desde a esperança de regeneração em D. Miguel, "rei salvador", na década de 1820, nas revoltas da Maria da Fonte e Patuléia, em 1845, em D. Pedro V, por volta de 1850... - "o 'esperar vagamente' que a felicidade 'escorra' de uma forma de governo", a "atitude 
característica de um povo que encara soluções para a vida nacional numa expectativa messiânica" (PIRES, 1992, p.252).

É interessante notar que o sebastianismo propagado pela intelligentsia republicana - designado por António José Saraiva de "sebastianismo vermelho" - visava à unidade coletiva através da restauração do sentimento de crença em um Messias que, envolvendo a nação como um todo, salvaria a Nação portuguesa. Lembremos que perspectiva idêntica havia estimulado o messianismo miguelista na década de 1820 . No entanto, a ideologia republicana substituía a base do fanatismo religioso pela da ciência.

Mais ou menos coetâneas dessa obra representante do "sebastianismo vermelho" foram o poema inconcluso "O Desejado" (1895-1898), de António Nobre, D. Sebastião (1898), de Luís de Magalhães, Encoberto (1904), de Sampaio Bruno. Essas obras corroboraram o reaparecimento do sebastianismo que foi retomado em A Mensagem (1934), de Fernando Pessoa, e que podia ser considerado adormecido desde a última reedição de "D. Sebastião, o Desejado (lenda nacional)", de F. M. Bordalo, publicado pelo Panorama de 02 de Dezembro de 1854 a 13 de Janeiro de 1855 para refutar o ressurgimento do mito no contexto de relativa paz materialista propiciada pelo fontismo e no qual ele não cabia.

Como pudemos ver através de Pátria e como veremos com "O Desejado", a decepção com a pátria, a frustração com a inoperância do processo de regeneração nacional, o sentimento generalizado de decadência pátria que perpassou o Portugal oitocentista - a "ressaca ideológica", segundo Joel Serrão - levou também, como já havia levado ao nacionalismo tradicionalista, ao ressurgimento do mito sebastianista, simbolicamente utilizado como opção temática e estética e apresentado como panaceia para o Portugal assolado, ${ }^{5}$ como redenção para a Pátria decaída e como sinônimo de nacio-

5 De acordo com Joel Serrão, “[...] o sebastianismo português, considerado de um ponto de vista histórico, é o reverso de uma complexa experiência coletiva, cujo anverso é o sentimento da decadência nacional” (Cf. “O tédio de António Nobre e a génese de 'O Desejado”, in Temas Oitocentistas. Vol. II, Livros Horizonte, Lisboa, 1978, p. 197). ${ }^{6}$ Em Camões: Os lusíadas e a Renascença em Portugal, Oliveira Martins escreveu: "Como Israel, nos seus cativeiros sucessivos, o português, abraçado à sua bíblia e enlevado no sonho messiânico do sebastianismo, amassado com lágrimas, balbuciará as estrofes de Camões sempre que vir apontar no céu uma aurora fugaz de renascimento, e sempre que contemple melancolicamente o crepúsculo saudoso do seu passado perdido”. 
nalidade. Associado ao republicanismo - como é o caso de Junqueiro - ou não, o sebastianismo era retomado nesse momento da vida nacional com o objetivo de restaurar a grandeza perdida de Portugal, de resgatá-lo, redimilo do estado de crise e decadência em que se encontrava. A reatualização do mito sebastianista por Guerra Junqueiro e António Nobre, entre outros, em 1896 e desde 1895 até 1898, respectivamente, a partir da História de Portugal de Oliveira Martins, foi feita no sentido em que as palavras resgatar, redimir, evidenciam a idéia que os norteou: a "redenção vem da Paixão”, portanto, a restituição das glórias passadas de Portugal seria conseqüência lógica e natural do estado de falência que o caracterizava.

Em “O Desejado", António Nobre ressalta - como já o fizera no Só - a grandiosidade do Portugal de outrora e o seu declínio no presente, mas anuncia que um futuro glorioso está à espera de Lisboa, sendo que esse ressurgir de Portugal associa-se ao retorno de D. Sebastião, o rei cujo destino era símbolo da pátria decaída, mas era também a representação de todos os sonhos e esperanças dos portugueses na possibilidade de redenção nacional.

A consumação do fracasso individual de Anrique narrada nesse poema, que é uma tentativa de epopéia, é relacionada à decrepitude de seu País através da alusão ao episódio histórico que efetivou a derrocada do Portugal imperial marítimo - simbolicamente invocado por aquele ao longo do poema “O Desejado". Se Anrique manifesta já em seu nome a ancestralidade que o alinha entre os célebres heróis do passado da nação portuguesa e os grandes feitos realizados por eles é a volta daquele tempo glorioso que, igualmente, encontra o reverso da moeda: a perda da soberania de seu País subseqüente ao "desastre de Alcacer-Kibir", isto é, à morte de D. Sebastião em África quando procurava, em uma ação de conquista tresloucada, expandir os territórios de seu reino. Assim, ao verso "A tosse veio... vós sabeis o fim", que evidencia a desgraça individual do herói menino, somam-se: "Foi a queda do Imperio do Occidente! / Foi o desastre de Alcacer-Kibir! / A Hespanha veio com Philipe á frente!" (NOBRE, 1945, p. 126), que, enunciados para descrever o fracasso daquele, subsumem o destino desse no destino de toda a coletividade e manifestam o aniquilamento de Portugal - destruição plena que extrapola os limites de não ser mais potência imponente, gloriosa, haja vista apresentar a perda da independência e soberania nacional, a qual, num certo sentido, é revivida de forma vexatória em 1890 com o Ultimatum. 
Anrique, outrora conde e rei; depois, transformado no "humilde Snr. Manoel dos Sofrimentos” (1945, p. 138), é símbolo, portanto, das épocas gloriosa e decadente de seu País, mas, a exemplo do próprio D. Sebastião, cabe a ele a ação determinante para o reerguimento do seu País: Anrique deve voltar a Portugal, onde "andam as almas todas quebrantadas” pela ruína nacional, e anunciar a "esse Povo do Mar" a vinda do Messias Redentor, o regresso de D. Sebastião; "gritar por essa rua” para que todos os portugueses "não fraqueje[m] nunca no caminho, / Que espere[m] em pé o seu D. Sebastião", pois “- Virá um dia o 'Sempre-Desejado” (NOBRE, 1945, p. 147). Desse modo, no Portugal decaído de fins de Oitocentos mantêm-se vivas as expectativas do Quinto Império português - reiteradas, um pouco mais tarde, pela Mensagem (1934) de Fernando Pessoa. Notemos, ainda, que no poema de Nobre a ação de Anrique ocorre depois dele ter-se tornado "Manoel dos Sofrimentos" e que o nome Manoel é uma derivação de Emanuel, que significa "Deus Conosco" e nos remete a Jesus Cristo. Assim, a transformação de Anrique, símbolo do Portugal ancestral, glorioso de Quinhentos, em Manoel dos Sofrimentos, que patenteia a derrocada daquele eu bem como de seu País, ressalta, juntamente com a missão do sujeito de anunciar a redenção a Portugal, a existência trágica e decadente de Anrique e, através desse, a concepção de que Portugal está integrado numa Paixão - que pode ser definida, segundo o Fernando Pessoa da Mensagem, pelos versos: "Os Deuses vendem quando dão / Compra-se a glória com desgraça” (2000, p. 16) -, e que será remido espiritualmente através da angústia, da dor, da queda, da perda da antiga glória que o caracterizou. O "Sempre-Desejado" pode ser considerado, portanto, a figura crística, divinamente investida para reerguer Portugal, para leválo ao Quinto Império, e cujo retorno Anrique, a exemplo de João Batista, anuncia.

Observemos também que a ação de Anrique pela regeneração de Portugal é catártica, uma vez que pode apagar o seu passado doloroso, uma vez que é a única saída possível ao eu abatido, arruinado. Perdida ao fim toda esperança individual, a ele resta, como vimos acima, "trabalhar" por aquele País, anunciando ao seu povo que um futuro glorioso está à espera de Lisboa, símbolo de Portugal. Trata-se, podemos dizer, de um messianismo sebastianista voltado antes para o caso individual e depois, como conseqüência, para os males pátrios. 
Está claro, portanto, que a Geração de 90, marcada pela decepção do Ultimatum, pela frustração com a decadência da Pátria, pela idéia generalizada na Europa de decadência, pelo Decadentismo finissecular, foi, entretanto, marcada por uma expectativa “miticamente positiva”. Desse modo, não é difícil reconhecer que

Os primeiros interpelantes radicais [os membros da Geração de 70, lembremos] da realidade nacional, instalaram-se na excepção [...] e este desenraizamento daquilo de quem ninguém pode desenraizar-se impunemente, ia convertê-los na primeira geração perdida de Portugal [...] mais tarde fascinada por uma outra miticamente positiva, a ínclita geração que Oliveira Martins ressuscitará à hora em que a utopia socialista da juventude naufraga. O que começara com Proudhon acabará com D. Sebastião e Nuno Álvares; o antiparlamentarismo de vocação revolucionária em cesarismo mais ou menos esclarecido (LOURENÇO, 1992, p. 92).

Nesse sentido, a "geração nacionalista e republicana" de fins de Oitocentos consistiu, para Oliveira Martins, aquilo que popularmente se chama de "tiro pela culatra", uma vez que elas valorizaram a partir da História de Portugal o patriotismo tradicionalista e o sebastianismo - recusados pelo historiador - como motivação para a unidade coletiva.

Se em Portugal a primeira geração romântica logo assimilou o ideário dessa sensibilidade literária que foi o marco da evolução da literatura moderna sobretudo no sentido de produzir uma literatura voltada às características genuínas e tipicamente nacionais - em prejuízo de uma outra parte daquele mesmo ideário, que foi o Romantismo negro -, naquele mesmo País, o Modernismo tardou a surgir (muito menos do ponto de vista estético-formal que do temático), uma vez que as gerações, às quais, seguindo o fluxo internacional, cabia assimilar e fazer medrar as idéias modernistas, estavam ainda presas ao tradicionalismo, ao messianismo, ao saudosismo (dos quais Nobre faz derivar a modernidade estética de sua poesia, lembremos). Isso pode ser explicado, em parte, pelo fato de a própria situação de instabilidade e decadência política e social de fins de Oitocentos e início de Novecentos ser favorável em Portugal à insistência na dicotomia passadopresente enfaticamente evidenciada desde Almeida Garrett e ao 
reaparecimento da expectativa de salvação messiânica, bem como à permanência de determinados aspectos da sensibilidade simbolista-decadentista, que avançou as primeiras décadas do século XX. Além disso, a ideologia que embasava o Republicanismo remontava aos esquemas mentais do Liberalismo Vintista e apresentava-se como uma nova fase do projeto de regeneração iniciado em 1820 e retomado em 1836 - o que o Republicanismo desejava era "dar um passo em frente mas regressando ao modelo 'revolucionário’ de 1820" (SERRÃO, 1990, p. 189). E não devemos esquecer que o projeto de regeneração do Republicanismo deixava claro o esquema a que o imaginário cultural e social de fim-de-século estava condicionado: a partir da constatação da falência e humilhação do presente, e sob o influxo da emoção, perspectivava-se tanto o passado glorioso como o futuro que haveria de resgatar a grandeza passada - em outras palavras, tratava-se da oposiçóo entre $o$ que é e $o$ que foi e entre $o$ que é e $o$ que deve ser e a necessidade de repetir no que deve ser, o que foi. Tudo isso, sem falarmos na questão africana e no programa colonialista subseqüente ao Ultimatum que muito contribuiu para a permanência daqueles ismos que nortearam a geração de 90 e para a "ressurreição" de Camões e da época renascentista. Apesar do Ultimatum, Portugal investiu, como vimos, na consolidação dos seus domínios em África e manteve-se como quarta potência colonizadora. A perspectiva, ilusória, de que a colonização das terras portuguesas em África recolocaria Portugal no papel de grande potência como fora em Quinhentos inflamava os espíritos e fazia emergir os símbolos daquela época: Camões e Os lusíadas, a ancestralidade gloriosa e mesmo a aventura sebastianista como, aliás, Oliveira Martins havia notado em 1872. ${ }^{6}$

Assim, do Portugal de Oitocentos, principalmente se comparado às civilizadas nações européias, parecia ser sempre procedente e atual a conclusão:

Um dia o instinto popular protesta, e a onda da anarquia rebenta. Uma vez impele-a a miragem do futuro: assim acontecera em França. Outra vez

6 Em Camões: Os lusíadas e a Renascença em Portugal, Oliveira Martins escreveu: "Como Israel, nos seus cativeiros sucessivos, o português, abraçado à sua bíblia e enlevado no sonho messiânico do sebastianismo, amassado com lágrimas, balbuciará as estrofes de Camões sempre que vir apontar no céu uma aurora fugaz de renascimento, e sempre que contemple melancolicamente o crepúsculo saudoso do seu passado perdido". 
arrebata-a a miragem do passado: assim acontecia em Portugal, que vivera três séculos de esperar a restauração do Quinto Império, católico e messiânico (OLIVEIRA MARTINS, 1991, p. 422).

\section{BIBLIOGRAFIA}

CATROGA, Fernando. Nacionalistas e Iberistas. In MATTOSO, José (dir.). História de Portugal. Vol. 5 (O Liberalismo. 1807-1890). Lisboa: Editorial Estampa, 1996.

FRANÇA, José-Augusto. $O$ Romantismo em Portugal. Estudo de factos socioculturais. 2a ed. Lisboa. Livros Horizonte. 1993.

JUNQUEIRO, Guerra. Finis Patriae. $7^{\text {a }}$ ed. Porto: Lello \& Irmão Editores, 1967. . Pátria. $5^{\text {a }}$ ed. Porto: Lello \& Irmão, Lda., [s.d.].

LOURENÇO, Eduardo. O Labirinto da Saudade. Lisboa: Publicações Dom Quixote, 1992. MARTOCQ, Bernard. Le pessimisme au Portugal. In Arquivos do Centro Cultural Português. Vol. V. Paris: Fundação Calouste Gulbenkian. 1992, p. 420-458.

NOBRE, António. Despedidas. Porto: Imprensa Moderna Ltd., 1945.

OLIVEIRA, Alberto de. Palavras Loucas. França Amado, 1984.

OLIVEIRA MARTINS, Joaquim Pedro. História de Portugal. Lisboa: Guimarães Editores, 1991.

PESSOA, Fernando. Mensagem. Lisboa: Assírio \& Alvim, 2000.

PIRES, António Machado. A Ideia de Decadência na Geração de 70. 2a ed. Lisboa: Ed. Vega, 1992.

QUEIROZ, Eça de. A Cidade e as Serras. 13ª ed. Porto: Aillaud \& Lelos Limitada, 1933. . Correspondência. (Leitura, coordenação, prefácio e notas de Guilherme de Castilho). Vol. II, Lisboa: Imprensa Nacional / Casa da Moeda, 1983.

. A Ilustre Casa de Ramires. São Paulo: Ed. Ática, 1997.

SARAIVA, António José. Para a história da cultura em Portugal. Vol. I. $7^{\text {a }}$ ed. Lisboa: Gradiva, 1995.

SERRÃO, Joel. “O tédio de António Nobre e a génese de 'O Desejado”, in Temas Oitocentistas. Vol. II. Lisboa. Livros Horizonte. 1978, p. 173-198.

. Da Regeneração à República. Lisboa: Livros Horizonte, 1990. 